\title{
The Impact of Parents Education Level on Career Aspiration Enhancement
}

\author{
Rahmi Dwi Febriani \\ amidwifebriani@gmail.com \\ Universitas Negeri Padang \\ Zadrian Ardi \\ zadrian@fip.unp.ac.id \\ Universitas Negeri Padang \\ Puji Gusri Handayani \\ pujigusrihandayani@gmail.com \\ Universitas Negeri Padang
}

\begin{abstract}
Career aspiration is a very important because aspiration is one indicator of individual career achievement in the future. Students who have prepared career options in the future have a better quality of life than those who have not prepared yet. But the fact in the field there are still students who are not interested to continue education to college, but education is the beginning of determining one's career. The formation of student attitudes about career aspirations is the result of interaction with the family. Of the various characteristics of the family, the level of parental education is one of the factors that affect the aspirations of a child's career.Parents who come from higher education tend to be able to create a child who has personally constructed and educated among them in the desire to obtain a successful career in the future.
\end{abstract}

Keywords: Parents Educational Level, Career Aspiration

(C) Published by Committee 5 th ICS

\section{PENDAHULUAN}

Karier merupakan bagian penting dalam kehidupan seseorang bahkan sebagian besar waktu, tenaga, dan pikiran banyak tercurah kepada hal-hal yang berkaitan dengan karier (Ardi, 2014; Ardi, Ibrahim, \& Said, 2012; Febriani, Yusuf, \& Iswari, 2016). Karier memiliki perspektif jangka panjang dan terkait dengan tujuan hidup (Hoekstra, 2011; King \& Hinds, 2011; Schaapsmeerders et al., 2013; Shultz \& Wang, 2011; Umberson, Pudrovska, \& Reczek, 2010). Karier sangat berkaitan dengan perkembangan personal seseorang dan menjadi bagian penting dalam kesuksesan hidup (Duffy, Dik, \& Steger, 2011; Komarraju, Musulkin, \& Bhattacharya, 2010; Ostrom, 2011). Setiap individu memiliki kebutuhan untuk mencapai kesuksesan (need for success) dalam kehidupan (Carsrud \& Brännback, 2011; Cheung \& Halpern, 2010; Ostrom, 2011; Schreuder \& 
Coetzee, 2011; Tims \& Bakker, 2010). Kebutuhan itu akan membentuk harapan dan keinginan individu tersebut. Setiap individu memiliki harapan dan keinginan yang berbeda-beda. Keinginan, harapan, cita-cita terhadap karier tertentu di masa depan disebut dengan aspirasi karier (Tri Triyono, 2017). Adanya aspirasi karier diharapkan akan mendorong siswa untuk berusaha mempersiapkan diri dalam mewujudkan karier yang diinginkan (Bryan, Young, Griffin, \& Henry, 2015; DeWitt et al., 2013; Guan et al., 2015; Hirschi, Freund, \& Herrmann, 2014; Linn, Palmer, Baranger, Gerard, \& Stone, 2015).

Aspirasi karier merupakan faktor penting dalam variabel pengembangan karier (Booth, 2005). Aspirasi karier siswa merupakan faktor yang berarti untuk pendidikan dan pilihan karier serta sebagai bayangan mobilitas sosial di masa depan (Christie, 2016; Francis, Mau, \& Archer, 2017; Haeger \& Deil-Amen, 2016; Stahl, 2017). Siswa yang mempunyai aspirasi karier yang lebih tinggi, konsekuensinya aspirasi pencapaian pendidikannya juga lebih besar (DeWitt \& Archer, 2015; Fuller, 2014; Khattab, 2015; $\mathrm{Xu}, 2016)$. Oleh sebab itu, aspirasi yang dimiliki siswa harus ditelusuri lebih mendalam, agar mampu mengenal siapa diri saya, mau kemana saya, sehingga dengan memiliki aspirasi karier yang jelas siswa dapat memilih dan merencanakan karier sesuai dengan minat, kemampuan, kapasitas, dan cita-citanya. Aspirasi karier tersebut dipengaruhi oleh banyak faktor salah satunya adalah tingkat pendidikan orangtua. Tingkat pendidikan orangtua diduga sebagai prediktor aspirasi karier anak-anak (Tri Triyono, 2017). Pembentukan sikap remaja tentang aspirasi karier merupakan hasil interaksi dengan keluarga (Febriani et al., 2016). Pembentukan aspirasi karier dimulai melalui pengenalan berbagai kemungkinan pilihan karier dalam keluarga (Schuette, Ponton, \& Charlton, 2012).

\section{PEMBAHASAN \\ KONSEP ASPIRASI KARIER}

Aspirasi merupakan salah satu aspek yang ada pada diri individu yang mengarahkan aktivitas individu untuk mencapai tujuan-tujuan tertentu. Aspirasi (orientasi masa depan) yang terdiri dari tiga tahapan yaitu motivasi, perencanaan, dan evaluasi (Cheng, 2012). Tahap pertama, remaja menetapkan tujuan berdasarkan kepentingan dan nilai-nilai mereka yang dikembangkan melalui proses pengalaman dan kemampuan sosial. Selanjutnya, tahap kedua, membangun sebuah rencana dan strategi berdasarkan pada pengetahuan untuk mewujudkan tujuan. Ketiga, mengevaluasi kemungkinan capaian tujuan tersebut. Sedangkan aspirasi karier menurut (Palmer \& Maramba, 2011; Rojewski, Lee, Gregg, \& Gemici, 2012) merupakan sejumlah motif, kebutuhan, keinginan, dan niat perilaku terhadap karier atau profesi tertentu.

Aspirasi karier adalah cita-cita atau harapan karier yang menimbulkan usaha untuk pencapaian harapan tersebut (Rojewski et al., 2012). Aspirasi karier dilihat dari seberapa banyak individu bercita-cita untuk mencapai kesuksesan, keberhasilan dalam bidang karier yang dipilih, dan sesuatu yang membantu dalam menetapkan tujuan karier, perkembang karier, dan mencapai kesuksesan karier (Jones, Griffith, Ubel, Stewart, \& Jagsi, 2016; Kim, O’Brien, \& Kim, 2016; Otto et al., 2017; Perry, Morris, Link, \& Leukefeld, 2016; Wang, Chow, Degol, \& Eccles, 2017). Aspirasi karier merupakan 
pendorong utama yang menggerakkan seseorang untuk mencapai apa yang diinginkannya terhadap kariernya kelak (Febriani \& Triyono, 2018; Triyono Triyono \& Febriani, 2018). Apabila seorang siswa memiliki aspirasi karier yang tinggi maka mereka akan berusaha dengan serius dan sungguh-sungguh untuk mencapai apa yang dicita-citakan tersebut (DeWitt \& Archer, 2015; Khattab, 2015; Kim et al., 2016; Stahl, 2017).

\section{KOMPONEN ASPIRASI KARIER}

Ada dua komponen aspirasi karier, yaitu aspirasi realistis dan aspirasi idealis (Rudman \& Phelan, 2010), berikut penjelasannya.

a. Aspirasi idealis

Aspirasi idealis yaitu keinginan yang tidak didasarkan pada kemampuan dan kesempatan yang ada dengan tingkat keberhasilannya rendah dan masih perlu diragukan. Disebabkan oleh kurangnya pertimbangan saat menetapkan suatu tujuan, sehingga terjadi ketimpangan antara keinginan, kemampuan diri, dan kemauan seseorang yang akan melakukan hal tersebut.

b. Aspirasi realistis

Aspirasi realistis yaitu keinginan yang didasarkan pada kemampuan dan kesempatan yang ada. Aspirasi ini berdasarkan harapan disertai perencanaan dan sarana yang mendukung dalam mencapai tujuan. Aspirasi yang pencapaian keberhasilannya masih sangat mungkin atau dengan kata lain, tingkat keberhasilannya tinggi. Kemungkinan yang besar itu didapatkan dari adanya pertimbanganpertimbangan yang disesuaikan dengan kemampuan dan ketekunan seseorang untuk mencapai suatu prestasi sehingga kemungkinan aspirasi bisa tercapai semakin tinggi.

Terdapat dua kandungan dalam aspirasi karier, yaitu komponen sikap dan komponen perilaku (Febriani et al., 2016; Rudman \& Phelan, 2010). Pertama, aspek yang terkait pada komponen sikap adalah (impian, harapan atau cita-cita, ambisi dan ide- ide). Kedua, komponen perilaku adalah perencanaan aktual, strategi, kerja keras, dan dedikasi yang ditunjukkan dengan usaha dalam mencapai tujuan arah karier yang ingin dicapai).

\section{PENGARUH TINGKAT PENDIDIKAN ORANGTUA TERHADAP ASPIRASI}

\section{KARIER SISWA}

Berdasarkan kajian literatur (library research) latar belakang keluarga merupakan salah satu faktor yang mempengaruhi aspirasi karier. Latar belakang keluarga, mencakup sosial ekonomi dan tingkat pendidikan orangtua. Tingkat pendidikan orangtua memiliki pengaruh terhadap aspirasi karier remaja (Archer, DeWitt, \& Wong, 2014; Correa-Velez, Gifford, McMichael, \& Sampson, 2017; Rimkute, Torppa, Eklund, Nurmi, \& Lyytinen, 2014; Rozek, Hyde, Svoboda, Hulleman, \& Harackiewicz, 2015; Sawitri, Creed, \& Zimmer-Gembeck, 2014; Vuolo, Mortimer, \& Staff, 2014). Hal tersebut diduga karena keluarga yang memiliki tingkat pendidikan yang tinggi, berpandangan bahwa pendidikan merupakan hal yang signifikan bagi kehidupan anaknya dan kesuksesan karier anak ke depannya (Rimkute et al., 2014; Sawitri et al., 2014; Vuolo et al., 2014). Tingkat pendidikan orangtua merupakan sesuatu yang besar pengaruhnya terhadap perkembangan karier anak (Hurlock, 2014). 
Orangtua yang memiliki tingkat pendidikan yang tinggi pada umumnya memiliki harapan yang tinggi juga terhadap anaknya agar memiliki pendidikan dan pekerjaan lebih baik dari orangtuanya (Ardi et al., 2012; Ardi \& Yendi, 2013, 2017; Daharnis \& Ardi, 2016). Orangtua yang demikian akan mendorong anaknya untuk memiliki capaian karier yang lebih tinggi dan sukses di masa depan, membantu meneksplorasi karier anak dengan cara membantu anak mendapatkan informasi tentang kelanjutan studi dan kariernya nanti (Tri Triyono, 2017). Orangtua adalah significant other bagi anak-anaknya yang akan dijadikan sebagai model dan panutan bagi mereka (Clark, 2015; Ing, 2014; Perera, 2014; Sovet \& Metz, 2014), begitu juga halnya dalam pendidikan dan karier ke depan.

\section{KESIMPULAN}

Aspirasi karier merupakan faktor penting dalam pengembangan karier siswa. Adanya aspirasi karier diharapkan akan mendorong siswa untuk berusaha mempersiapkan diri dalam mewujudkan karier yang diinginkan. Oleh sebab itu, aspirasi yang dimiliki siswa harus ditelusuri lebih mendalam, agar mampu mengenal siapa diri saya, mau kemana saya, sehingga dengan memiliki aspirasi karier yang jelas siswa dapat memilih dan merencanakan karier sesuai dengan minat, kemampuan, kapasitas, dan cita-citanya. Semua ini tidak terlepas dari dukungan keluarga terutama orangtua. Orangtua menjadi significant other bagi anak-anaknya yang akan dijadikan model, maka dari itu latar belakang keluarga terutama tingkat pendidikan orangtua menjadi salah satu penentu tingkat aspirasi karier siswa. Orangtua yang memiliki tingkat pendidikan yang tinggi pada umumnya memiliki harapan yang tinggi juga terhadap anaknya agar memiliki pendidikan dan pekerjaan yang lebih baik dari orangtuanya. Orangtua yang demikian akan mendorong anaknya untuk memiliki capaian karier yang lebih tinggi dan sukses di masa depan.

\section{KEPUSTAKAAN}

Archer, L., DeWitt, J., \& Wong, B. (2014). Spheres of influence: What shapes young people's aspirations at age 12/13 and what are the implications for education policy? Journal of Education Policy, 29(1), 58-85.

Ardi, Z. (2014). Cita-cita Perkerjaan dan Pilihan Peminatan Siswa Sekolah Menengah Atas Negeri di Sumatera Barat.

Ardi, Z., Ibrahim, Y., \& Said, A. (2012). Capaian Tugas Perkembangan Sosial Siswa dengan Kelompok Teman Sebaya dan Implikasinya terhadap Program Pelayanan Bimbingan dan Konseling. Konselor, 1(2).

Ardi, Z., \& Yendi, F. M. (2013). Konseling Online: Sebuah Pendekatan Teknologi Dalam Pelayanan Konseling. Jurnal Konseling Dan Pendidikan, 1(1), 1-5.

Ardi, Z., \& Yendi, F. M. (2017). Students Attitude Towards LGBTQ; the Future Counselor Challenges. Jurnal Konseling Dan Pendidikan, 5(2), 74-79.

Booth, C. S. (2005). The Relationship among Career Aspiration, Multiple Role Planning Attitudes, and Wellness in African-American and Caucasian Undergraduate Women (Dissertation). University of North Carolina, Greensboro.

Bryan, J., Young, A., Griffin, D. C., \& Henry, L. (2015). Preparing students for higher education: How school counselors can foster college readiness and access. Higher Education and Society. New York: Peter Lang, 2.

Carsrud, A., \& Brännback, M. (2011). Entrepreneurial motivations: what do we 
still need to know? Journal of Small Business Management, 49(1), 9-26.

Cheng, M. (2012). Factors influencing adolescents' career aspirations: a perspective from Hong Kong. HKU Theses Online (HKUTO).

Cheung, F. M., \& Halpern, D. F. (2010). Women at the top: powerful leaders define success as work+ family in a culture of gender. American Psychologist, 65(3), 182.

Christie, F. (2016). Careers guidance and social mobility in UK higher education: practitioner perspectives. British Journal of Guidance \& Counselling, 44(1), $72-85$.

Clark, R. M. (2015). Family life and school achievement: Why poor black children succeed or fail. University of Chicago Press.

Correa-Velez, I., Gifford, S. M., McMichael, C., \& Sampson, R. (2017). Predictors of secondary school completion among refugee youth 8 to 9 years after resettlement in Melbourne, Australia. Journal of International Migration and Integration, 18(3), 791-805.

Daharnis, D., \& Ardi, Z. (2016). THE COMPATIBILITY STUDENT CHOICE OF UNIVERSITY MAJORING; A PRELIMINARY STUDIES. GUIDENA: Jurnal Ilmu Pendidikan, Psikologi, Bimbingan Dan Konseling, 6(1), 101109.

DeWitt, J., \& Archer, L. (2015). Who aspires to a science career? A comparison of survey responses from primary and secondary school students. International Journal of Science Education, 37(13), 2170-2192.

DeWitt, J., Osborne, J., Archer, L., Dillon, J., Willis, B., \& Wong, B. (2013). Young children's aspirations in science: The unequivocal, the uncertain and the unthinkable. International Journal of Science Education, 35(6), 10371063.

Duffy, R. D., Dik, B. J., \& Steger, M. F. (2011). Calling and work-related outcomes: Career commitment as a mediator. Journal of Vocational Behavior, 78(2), 210-218.

Febriani, R. D., \& Triyono, T. (2018). Faktor Penghambat Pelaksanaan Evaluasi Program Bimbingan dan Konseling oleh Guru Bimbingan dan Konseling. Jurnal Counseling Care, 2(1), 21-27.

Febriani, R. D., Yusuf, A. M., \& Iswari, M. (2016). Perbedaan Aspirasi Karier Siswa ditinjau dari Jenis Kelamin, Jurusan, dan Tingkat Pendidikan Orangtua serta Implikasinya terhadap Pelayanan Bimbingan dan Konseling. Konselor, 5(3), 160-171.

Francis, B., Mau, A., \& Archer, L. (2017). The construction of British Chinese educational success: exploring the shifting discourses in educational debate, and their effects. Journal of Ethnic and Migration Studies, 1-15.

Fuller, C. (2014). Social capital and the role of trust in aspirations for higher education. Educational Review, 66(2), 131-147.

Garcia, P. R. J. M., Restubog, S. L. D., Bordia, P., Bordia, S., \& Roxas, R. E. O. (2015). Career optimism: The roles of contextual support and career decision-making self-efficacy. Journal of Vocational Behavior, 88, 10-18.

Guan, Y., Wang, F., Liu, H., Ji, Y., Jia, X., Fang, Z., ... Li, C. (2015). Careerspecific parental behaviors, career exploration and career adaptability: A 
three-wave investigation among Chinese undergraduates. Journal of Vocational Behavior, 86, 95-103.

Haeger, H., \& Deil-Amen, R. (2016). Cooling Out and Leveled Aspirations among Low-Income University STEM Students. In Paradoxes of the Democratization of Higher Education (pp. 69-96). Emerald Group Publishing Limited.

Hirschi, A., Freund, P. A., \& Herrmann, A. (2014). The career engagement scale: Development and validation of a measure of proactive career behaviors. Journal of Career Assessment, 22(4), 575-594.

Hoekstra, H. A. (2011). A career roles model of career development. Journal of Vocational Behavior, 78(2), 159-173.

Hurlock, E. B. (2014). Perkembangan Anak Edisi Keenam Jilid I. Jakarta. Penerbit Erlangga.

Ing, M. (2014). Can parents influence children's mathematics achievement and persistence in STEM careers? Journal of Career Development, 41(2), 87103.

Jones, R. D., Griffith, K. A., Ubel, P. A., Stewart, A., \& Jagsi, R. (2016). A mixed-methods investigation of the motivations, goals, and aspirations of male and female academic medical faculty. Academic Medicine, 91(8), 1089-1097.

Khattab, N. (2015). Students' aspirations, expectations and school achievement: what really matters? British Educational Research Journal, 41(5), 731-748.

Kim, Y. H., O’Brien, K. M., \& Kim, H. (2016). Measuring Career Aspirations Across Cultures: Using the Career Aspiration Scale With Young Korean Women. Journal of Career Assessment, 24(3), 573-585.

King, C. R., \& Hinds, P. S. (2011). Quality of life: from nursing and patient perspectives. Jones \& Bartlett Publishers.

Komarraju, M., Musulkin, S., \& Bhattacharya, G. (2010). Role of student-faculty interactions in developing college students' academic self-concept, motivation, and achievement. Journal of College Student Development, 51(3), 332-342.

Linn, M. C., Palmer, E., Baranger, A., Gerard, E., \& Stone, E. (2015). Undergraduate research experiences: impacts and opportunities. Science, 347(6222), 1261757.

Ostrom, E. (2011). Background on the institutional analysis and development framework. Policy Studies Journal, 39(1), 7-27.

Otto, K., Otto, K., Roe, R., Roe, R., Sobiraj, S., Sobiraj, S., ... Garrido Vásquez, M. E. (2017). The impact of career ambition on psychologists' extrinsic and intrinsic career success: The less they want, the more they get. Career Development International, 22(1), 23-36.

Palmer, R. T., \& Maramba, D. C. (2011). African American male achievement: Using a tenet of critical theory to explain the African American male achievement disparity. Education and Urban Society, 43(4), 431-450.

Perera, L. D. H. (2014). Parents' attitudes towards science and their children's science achievement. International Journal of Science Education, 36(18), 3021-3041. 
Perry, B. L., Morris, E. W., Link, T. C., \& Leukefeld, C. (2016). From Athletes to Astrophysicists: Gender Differences in Patterns and Predictors of Career Aspirations in Pre-Adolescence. Social Sciences, 5(1), 5.

Rimkute, L., Torppa, M., Eklund, K., Nurmi, J.-E., \& Lyytinen, H. (2014). The impact of adolescents' dyslexia on parents' and their own educational expectations. Reading and Writing, 27(7), 1231-1253.

Rojewski, J. W., Lee, I. H., Gregg, N., \& Gemici, S. (2012). Development patterns of occupational aspirations in adolescents with high-incidence disabilities. Exceptional Children, 78(2), 157-179.

Rozek, C. S., Hyde, J. S., Svoboda, R. C., Hulleman, C. S., \& Harackiewicz, J. M. (2015). Gender differences in the effects of a utility-value intervention to help parents motivate adolescents in mathematics and science. Journal of Educational Psychology, 107(1), 195.

Rudman, L. A., \& Phelan, J. E. (2010). The effect of priming gender roles on women's implicit gender beliefs and career aspirations. Social Psychology.

Sawitri, D. R., Creed, P. A., \& Zimmer-Gembeck, M. J. (2014). Parental influences and adolescent career behaviours in a collectivist cultural setting. International Journal for Educational and Vocational Guidance, 14(2), 161180.

Schaapsmeerders, P., Maaijwee, N. A., van Dijk, E. J., Rutten-Jacobs, L. C., Arntz, R. M., Schoonderwaldt, H. C., ... de Leeuw, F.-E. (2013). Long-term cognitive impairment after first-ever ischemic stroke in young adults. Stroke, 44(6), 1621-1628.

Schreuder, D., \& Coetzee, M. (2011). Careers An Organisational Perspectice. Juta and Company Ltd.

Schuette, C. T., Ponton, M. K., \& Charlton, M. L. (2012). Middle school children's career aspirations: Relationship to adult occupations and gender. The Career Development Quarterly, 60(1), 36-46.

Shultz, K. S., \& Wang, M. (2011). Psychological perspectives on the changing nature of retirement. American Psychologist, 66(3), 170.

Sovet, L., \& Metz, A. J. (2014). Parenting styles and career decision-making among French and Korean adolescents. Journal of Vocational Behavior, 84(3), 345-355.

Stahl, G. (2017). Aspiration paradoxes: working-class student conceptions of power in "engines of social mobility." International Journal of Qualitative Studies in Education, 1-15.

Tims, M., \& Bakker, A. B. (2010). Job crafting: Towards a new model of individual job redesign. SA Journal of Industrial Psychology, 36(2), 1-9.

Trevino, N. N., \& DeFreitas, S. C. (2014). The relationship between intrinsic motivation and academic achievement for first generation Latino college students. Social Psychology of Education, 17(2), 293-306.

Triyono, T. (2017). KONTRIBUSI DUKUNGAN ORANGTUA TERHADAP TINGKAT ASPIRASI PENDIDIKAN LANJUTAN. Jurnal Pelangi, 8(2).

Triyono, T., \& Febriani, R. D. (2018). Persepsi Peserta Didik Sekolah Menengah Atas Terhadap Pendidikan Lanjutan. Edudikara: Jurnal Pendidikan Dan Pembelajaran, 3(1), 70-77. 
Umberson, D., Pudrovska, T., \& Reczek, C. (2010). Parenthood, childlessness, and well-being: A life course perspective. Journal of Marriage and Family, 72(3), 612-629.

Vuolo, M., Mortimer, J. T., \& Staff, J. (2014). Adolescent precursors of pathways from school to work. Journal of Research on Adolescence, 24(1), 145-162.

Wang, M.-T., Chow, A., Degol, J. L., \& Eccles, J. S. (2017). Does Everyone's Motivational Beliefs about Physical Science Decline in Secondary School?: Heterogeneity of Adolescents' Achievement Motivation Trajectories in Physics and Chemistry. Journal of Youth and Adolescence, 46(8), 18211838.

Xu, Y. J. (2016). Aspirations and application for graduate education: gender differences in low-participation STEM disciplines. Research in Higher Education, 57(8), 913-942. 